priority, although the respondents felt that it was effective and important (but gave no evidence for this). The respondents felt that general practice was the best place to give this advice and that they had the necessary skills, although few had received any training. Barriers to providing the advice were, as usual, lack of time and resources as well as lack of contact with women planning to conceive. The authors suggest that research is needed into ways that preconception care can be provided. There seemed little appreciation of alternative views that this task might be more suited to a public education campaign that might also reach those women who do not attend general practice.

Reviewed by Gill Wakley, MD, MFPP Visiting Professor in Primary Care Development, Staffordshire University and Freelance General Practitioner and Writer, Abergavenny, UK

\section{NEWS ROUNDUP}

\section{Young people ignorant about STIs}

The American Social Health Association (ASHA) questioned more than 1000 people aged between 18 and 35 years of age. Although $84 \%$ said that they took precautions to prevent sexually transmitted infections (STIs), the follow-up questions showed that this was not true. Although 93\% thought that their partner did not have a STI, one in three had never discussed STIs with their partners - so how did they know? Of those questioned, $68 \%$ were not worried that they might contract a STI: the well-known 'It won't happen to me' scenario. Nearly half used no protection during vaginal intercourse, $66 \%$ used no protection during anal intercourse and only $9 \%$ used any protection for oral sex. The survey was mainly designed to identify the level of knowledge about hepatitis A and B, both of which can be transmitted sexually. The authors of the report were concerned by the results that more than half of those surveyed didn't know that hepatitis A and B can be sexually transmitted, the respondents were unaware that vaccines were available, and did not know if they had been immunised against either of the infections. Although hepatitis B is much more infectious than human immunodeficiency virus, young people seemed to know less about it. Further information is available at: http://www. ashastd.org/press/040504viral hepatitis.html.

\section{Department of misinformation}

A press release from the 'Family Research Council' quotes Kathleen M Gallagher, director of pro-life activities for the New York State Catholic Conference, commenting on a report advocating over-the-counter emergency contraception (EC). Gallagher said "Havesi's report promotes dangerous public policy that could result in the repeated distribution of mega doses of hormones to girls and women without physician oversight or parental supervision for children. Even the FDA has stated that the effect of repeated use of these pills is unknown. These chemicals sometimes cause abortions by
Serum medroxyprogesterone acetate levels in new and repeat users of depot medroxyprogesterone acetate at the end of dosing interval. Smit J, Botha J, McFadyen L, et al. Contraception 2004; 69: 3-7

This study was undertaken as there was no research evidence of the serum levels of serum medroxyprogesterone acetate (MPA) in the African population. A total of 97 women were recruited and 94 returned for a follow-up visit. Some $24 \%$ of the population had used the method for three or fewer injections and the remainder had been using depot medroxyprogesterone acetate (DMPA) for more than a year. The serum MPA was measured in a sample of blood taken before the next injection at the follow-up visit. The results showed no consistent level of MPA and no statistical

destroying growing embryos and, through overthe-counter availability, women would be denied even this basic knowledge. Women deserve better." Perhaps this spokeswoman should gain some basic knowledge about the dose of progestogen-only EC and its actions? Readers of this Journal are often unaware of the dangerous myths promulgated by people with a fixed-belief system and should take every opportunity to dispel the misinformation. The Family Research Council has as its motto 'Defending Family, Faith and Freedom' and its website contains some gems of biased reporting. Further information is available at: http://www.frc.org.

\section{Good news about sex and age}

A Swedish study reported on several news gathering sites reveals that nearly all 70 -year-olds would be sexually active if they could. Nils Beckham from Gothenburg University polled 165870 -year-olds. In 1971 , only $0.8 \%$ of 70 year-old women said they were sexually active, now the proportion is $13 \%$. Many more women of this age are living with a partner or are married as compared with 30 years ago. The proportion of men claiming to be sexually active has risen from $50 \%$ in 1971 to $69 \%$ today. More men tended to have partners who were younger than themselves. Unfortunately, the source for this information is in Swedish, but searching for this information on Google provoked much hilarity. (NB. The author thanks Susan Quilliam for drawing this press release to her attention.)

\section{Topiramate and COC}

The levels of interactions between topiramate and a combined oral contraceptive (COC) (containing $35 \mu \mathrm{g}$ ethinylestradiol and norethindrone) were compared with those between carbamazepine and the $\mathrm{COC}$ in a recent publication. ${ }^{1}$ Hormone levels were measured over two cycles in groups of women on different doses of topiramate and in between 30 and 35 . Small, non-significant changes occurred in the groups of women taking any of the doses of topiramate compared with a marked difference in the group taking carbamazepine. The levels of oestrogen in the latter group were significantly lowered. The one group whose basal metabolic indexes were

difference when allowing for body mass index BMI) and length of time using the method. There was only one woman recorded as being below the level of $0.1 \mathrm{mg} / \mathrm{ml}$ of MPA (the level at which ovulation is inhibited).

This study confirms that the levels of MPA at the time of the next injection are not related to BMI or length of time used and levels are very variable in any population. Almost all women will have levels of MPA that will still suppress ovulation. We should be wary of the occasional woman whose levels are low enough not to inhibit ovulation if she is late with an injection.

Reviewed by Judy Murty, DRCOG, MFFP

SCMO, Contraceptive and Sexual Health Services, Leeds, UK

authors concluded that topiramate, at daily doses of $50-200 \mathrm{mg}$, does not interact with a COC containing norethindrone and ethinylestradiol and it seems plausible to generalise this finding to other COCs. Women taking topiramate can be reassured that no extra contraceptive precautions or increased dose of COC is required.

Penovich P. Effect of topiramate or carbamazepine on the pharmacokinetics of an oral contraceptive containing

norethindrone and ethinyl estradiol in healthy obese and

\section{Condoms and HPV infection}

We know that some infections with human papilloma virus (HPV) contribute to the development of cervical cancer. A commentary from the American journal reporting on control measures for cancer ${ }^{1}$ discusses what advice we should be giving to patients about the role of condoms. The commentary reviews a couple of studies from The Netherlands that suggested that condom use might be associated with the regression of cervical intra-epithelial neoplasia and in men with HPV-related penile lesions. The studies concluded that the results showed that the lesions regressed in the group that used condoms compared with the carefully matched group not using condoms. HPV was more quickly cleared in the condoms users also. The researchers suggest we should be advocating condom use as a means of promoting HPV clearance and regression of lesions. However, the commentary points out some caveats. The studies showed little difference in those people who had lesions for more than 6 mmonths. Most HPV infections are transient and are likely to clear anyway. Many of the infections that we detect in clinical practice will have been present for longer than 6 months. However, using a condom is likely to prevent re-infection with HPV, infection with another type of HPV or other infections. As usual, further research is needed!

News and views. Can condoms help clear HPV? CA Cancer J Clin 2004; 54: 69-71.

Reviewed by Gill Wakley, MD, MFPP Visiting Professor in Primary Care Development, Staffordshire University and Freelance General Practitioner and Writer, Abergavenny, UK

hospital specialists know less about contraception than they think.

This book is written from a UK context, encill written and also demonstrates positive attitude to caring for the whole patient.

The authors are all hospital-based consultants in obstetrics and gynaecology. Hospital-based aspects of the speciality are accurate and up to date, however the contraception section is disappointing. The authors think that progestogen implants such as Implanon ${ }^{\circledR}$ are biodegradable and do not require removal. The progestogen-only vaginal Fem-ring ${ }^{\circledR}$ is described as if it is already in clinical use. It is hard to resist the notion that audience. It would provide a good introduction to the specialty for medical students and also an excellent concise revision source for doctors preparing for DRCOG and MFFP examinations.

Reviewed by Kate Weaver, MB ChB, MFFP Staff Grade Doctor in Reproductive Health Care, Edinburgh, UK 
Hysterectomy, Vaginal Repair, and Surgery of Stress Incontinence (5th edn). S Haslett, M Jennings, $\mathrm{H}$ Walsgrove and $\mathrm{W}$ Weatheritt. Beaconsfield, UK, 2003. ISBN: 0906584531. Price: £4.95. Pages: 48 (paperback)

This is a booklet designed to answer many of the questions women have regarding their surgery. This fifth edition expands on previous editions with the development in surgical and alternative options such as operations involving tension-free vaginal tape. The original two authors of the booklet have been joined by two co-authors for this edition, all with extensive experience and an interest in women's health.

The booklet covers anatomy and surgery with some information on complications, preoperative and admission preparation, general care after the operation, postoperative exercises and care after leaving the hospital.

The anatomy and surgery chapters include useful illustrations describing the individual surgical procedures, which are relevant and clear with respect to the subject matter and will aid the reader. The information covered in the opening sections particularly encourages women to discuss with the professionals any queries and doubts about their procedure and the choices available.

The section on general care after the operation comprehensively covers all aspects from analgesic options, emotional reactions, bladder and bowel care and prevention of thrombosis. The use of photographs in the section covering exercises is a useful reference tool for the correct undertaking of the exercises. The importance of continuing the exercises long-term is emphasised well in this section. Long-term issues such as the menopause and hormone replacement therapy are not comprehensively addressed but are adequate for the text, and the authors have included references for further reading and useful contacts.

This booklet is highly relevant to women, and their families, facing this type of surgery. It will address many of the issues that patients may have failed to ask about in clinics when faced with the prospect of surgery. Whilst a professional may think that they are aware of all the issues covered, reading this booklet helps to focus the consultation and provide practical information the patient requires. Patients would find this an excellent and well thought out reference point, which will promote their long-term mental and physical well-being postoperatively.

Reviewed by Allison Tait, RGN, HV

Family Planning Nurse and Menopause Nurse Counsellor, Dean Terrace Family Planning and Well Woman Clinic, Edinburgh, UK

Quickies: A Handbook of Brief Sex Therapy. Shelley K Green and Douglas Flemens (eds). New York, NY: W W Norton \& Company, 2004. ISBN: 039370381 9. Price: \$28.00. Pages: 250 (hardback)

The double entendre title is amusing. The bright red glossy cover is seductive. So is 'Quickies' simply a pretty face - or does it contain relevant insights and useful material? The answer is yes and no. The book's 12 chapters contain a series of essays by brief therapists who work in the field of sexuality. The text is always direct, often personal, and the individual authors have clearly been instructed to include as many case histories as possible in their contributions. The result is an easy and entertaining read, the anecdotes in particular providing clear examples of brief therapy practice. But the book still left me with a number of doubts. Who is it aimed at? The authors say they want to reach other therapists, particularly those who do not currently feel able to address sexual issues with clients - and certainly one needs a therapeutic background to appreciate the book.

But those therapists not already trained in sex therapy would surely not leap into those deep waters on the strength of reading this book. And those who are already trained might feel alienated; the authors are unapologetically critical of standard approaches, and occasionally defensive about 'brief' work itself.

Does the book fulfil its brief? It certainly isn't the handbook that the subtitle claims; some of the chapters explain 'how to' use brief therapy, but the coverage is neither comprehensive nor instructional. The book does, however, fulfil many of the authors' other stated aims, namely to showcase the talents of existing therapists, to stimulate discussion and exploration of the field, and to encourage the viewing of brief approaches as more than a 'Band-Aid' (their word, not mine).

Equally, the presuppositions that run through the book must be useful to any therapist. The importance of normalising the client's experience; of validating what is rather than what 'should' be; of giving credence to the clients, the usefulness of their 'problem' symptoms and the solutions they themselves suggest. The idea too that 'the best therapy is often ... the quickest' seems to be a useful antidote to some existing approaches; but then this reviewer has always been in favour of challenging the establishment!

In short, this book won't convince you to use brief therapy with sexual problems - and even once convinced, it won't in itself resource you to start practising. But it is worth reading if you want an enthusiastic insight, a taster that could well inspire you to explore further.

Reviewed by Susan Quilliam, BA, MNLP Freelance Writer, Broadcaster and Agony Aunt, Cambridge, $U K$

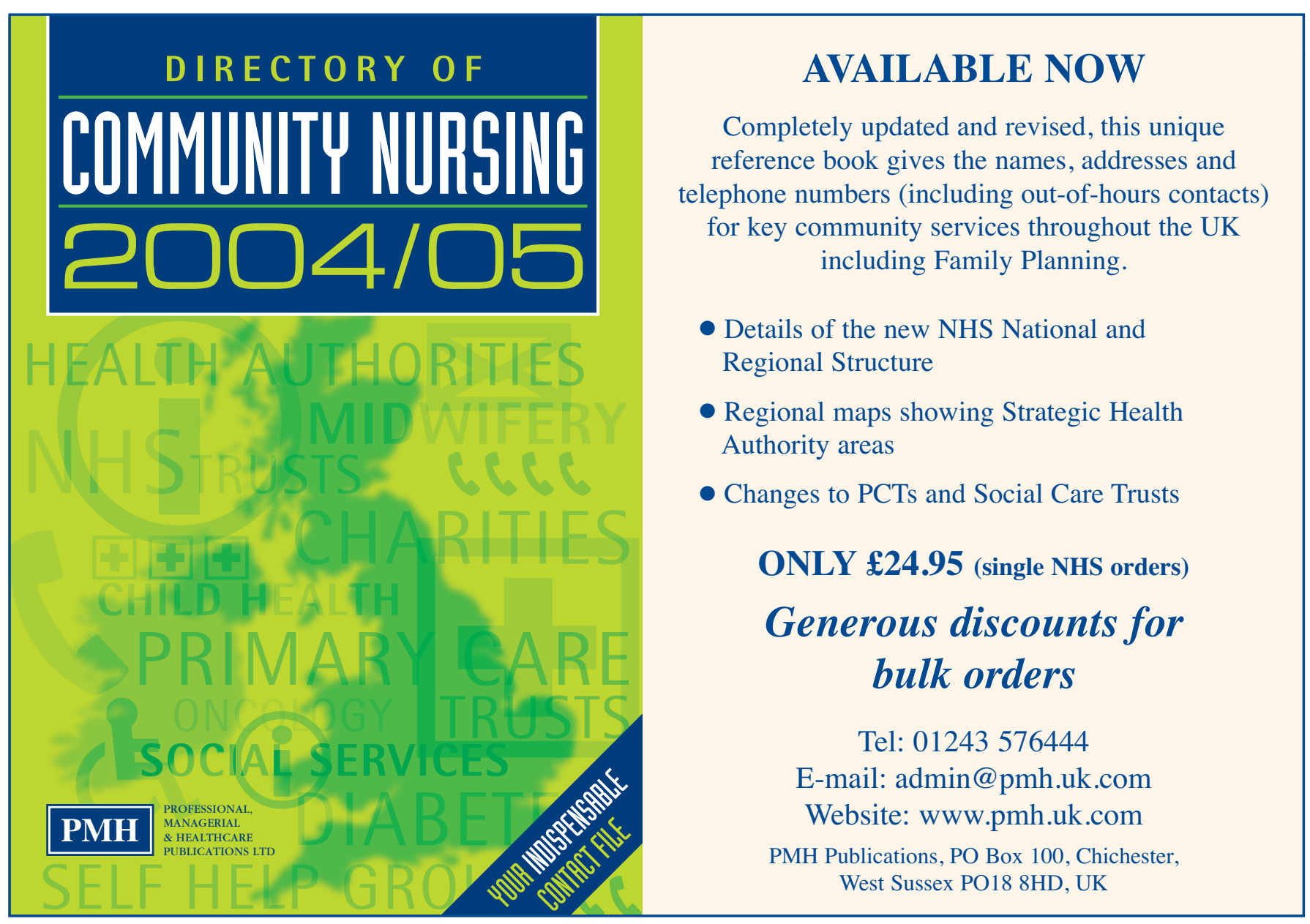

